Influence on Traumatic Lesions.

The influence of oral sepsis on traumatic lesions must not be forgotten. As an example, a young man injures his knee at footbail. The mischief does not yield to treatment, and a cluronic synovitis is established. Removal of dental sepsis is followed by complete recovery.

Oral sepsis may penetrate the orifices of the parotid and submaxillary glands, and set up a clronic inflammation in the ducts and substance of the glands. Acute septic infection, which used to be common in the parotid and was often fatal, has become rare, because one of the duties of the nurse attending exhausted medical and surgical patients is to keep the mouth as clean as possible. There are other and fortunately rare cases due to pyorrhoea. One was reported in the Lancet a short time since. The patient had a perfect cesspool in the upper jaw from pyorrhoea, ulceration of adjacent cheek, a spreading cellulitis, which led the way to the cavernous sinus; the left crus cerebri was involved, with a corrcsponding right-sided hemiplegia. Death onsued in twelve hours from profound septicaemic coma six days after the onset of symptoms.

No yatient who has been under trealment for Vincent's angina should be discharged as cured until swabs from around the teeth are negative and free from the fusiform bacillus regarded as the cause of Vincent's angina.

Chronic nasopharyngitis, septic bronchitis, skin troubles, middle-ear disease, are some of the other diseases which may be due to or influenced by oral sepsis.

\section{Oral Sepsis in Children}

I am sure we all recognize the serious effect of oral sepsis in children. Their physical and often their mental growth is retarded. A common result in clildren is gastro-intestinal disorder, as evidenced by gastric and abdominal pain, diarrhoea of an offensive character, with much undigested food in the motions, sleeplessness, loss of appetite, marked wasting, and pallor. Many of the septic teeth are tender, with the result that we get imperfect mastication, and this, combined with the sepsis, produces the trouble. Night sweats are often present; tuberculosis is suspected, slight albuminuria may be found, and nephritis sometimes intervenes.

Dr. Still lays particular stress on oral sepsis due to dental disease, which he says is so common in children, and enlarged glands in the neck are also common; but it must be remembered that pharyngeal conditions, adenoid hypertrophy, and tonsillar enlargement have much to answer for. Tubercle bacilli have been demonstrated in diseased teeth; but even if it could be proved that these never make their way directly from a diseased or septic tooth it wonld still be almost certain that this disease in children is indirectly responsible in no small number of cases for the tuberculous infection of glands. Indeed, in the child of tuberculous family it is a powerful predisposing cause of tuberculous infection perhaps down the whole cervical chain.

The failure of an infant to gain weight is frequently associated with oral sepsis in a nursing mother, and the removal of the septic teeth has been followed by a rapid improvement in the weight of the child. Many of the children vomit the milk after being fed. This points to its containing some toxin which the gastric mucosa will not tolerate.

An interesting case-quoted recently-is that of a child suffering from diarrhoea which failed to yield to treatment. The mother was found to have a very septic mouth, and as she persisted in lissing the child they were separated for a while, the result being that the intestinal trouble cleared up forthwith.

Even from this brief survey it is clear that oral sepsis may affect the organism in different ways-indeed, may influence the course of most diseases; and Dr. Stanley Colyer sums up the position thus:

"The somewhat bizarre nature of the effects that have been attributed to dental sepsis may at first sight make the relationship appear improbable, but when once the principles that underlie the subject have been grasped it will be realized that the conclusions are a necessary outcome. In all diseases there are two factors at least-the seed and the soil-without which disesse cannot exist. The seed varies, the soil varies; never are the two the same, never is the relation repeated. This is why variation in disease is common, and in no two persons does it run a precisely similar course. Dental sepsis is but a comprehensive term to include various septic conditions in the mouth-it is not a disease. The varms cansing the sepsis vary, and so the germs passing into the germs causing the sepsis vary, and so the germs passing into the people. It cannot be said why germs of a particular kind entering one body produce a septicaemia and in another an infective endocarditis, or why a toxin in one will produce an anaemia and in another a neuritis; but that such is the case seems almost certain, and for the time being we mus rest content with the fact."

The tendency in medicine in the present day seems to be to divide disease into two classes-those due to germ infection, and those not due to this cause; and if, in any case coming within one category, we inquire whether there is a source of infection and test the results of treatment directed to its removal, we may arrive at a conclusion of practical valne.

We cannot expect to cure all our cases, even by the most drastic treatment, but we must not argue from the particular to the general in cases of failure. There may be other foci of infection: an intestinal tract may be permanently infected, or, as in some of the most chronic cases, the damage may be beyond repair. Time will not permit of my saying more on this far-reaching subject. If $I$ have succeeded in a very small way in calling attention to its importance my end is attained.

Since the foregoing notes were written an article has appeared in the Lancet (April 1st) which, while giving oral sepsis its due in playing an undoubtedly important part in the causation of general disease, points out the great need there is for more conclusive pathological proof than is often forthcoming in support of the clinical evidence available.

As giving some account of the extreme divergence of opinions naturally springing from the present state of insufficient pathological authority on this subject, and at the same time presenting a dispassionate view of the extreme schools of thought, this article is most interesting and suggestive. Professor Martin Fisher of America-a well-known writer on infections of the mouth-puts forward dental infeeticn as a cause of very many conditions; whereas Professor Hugo Schottmüller of Hamburg, whilst conceding that oral sepsis, like infection elsewhere, is capable of affecting the general health, does not believe that it acts as a direct canse of general disease. As the writer goes on to point out, dental infections may often be so situated that there is no large outpouring of bacteria into the circulation, yet there is a possibility of small doses of bacteria escaping from time to time and altering the bodily resistance. It is quite certain that no one is in a position to deny that oral sepsis constitutes a potentially and often an actually dangerous condition, and anyone with experience amongst hospital patients especially cannot fail to be struck by the appalling prevalence of oral sepsis. The result of treatment is in very many cases followed by a cure of some other trouble or disease due to it. Whilst every case must benefit generally from its treatment, the great thing to which we should direct our energies is to make pathological proof more convincing. When this has been achieved I am sanguine enough to believe that very great and more certain results will follow the judicious treatment of oral sepsis.

\section{THE SOLUBILITY OF QUININE HYDROCHLORIDE.}

\section{J. HAMILTON CRAWFORD, M.B., M.R.C.P.E}

(Department of Pharmacology, University of Edinburgb).

THe quinine salt most generally used formerly was the sulpLate, but more recently the lydrochloride has come into favour as being much more soluble in water. The sulphate is taken up only by 725 parts of water, while the hydrochloride is dissolved by 35 parts. Each is readily dissolved with acid, the bisulphate in 9 parts and the acid hydro. chloride in 0.6 part of water. The presence of excess of acid is a disadvantage in intramuscular or intravenous injection, and here especially the solubility of the neutral hydrochloride weighs heavily in its favour. In the intravenous injection especially the hydrochloride is likely to be injected, not in distilled water but in saline solution or in Ringer's solution, and it is therefore of importance to ascertain whether its solubility is affected by the constituents of these fluids. The saline solution used was 0.85 per cent. $\mathrm{NaCl}$. The Ringer's solution was made up to contain $\mathrm{NaCl} 0.85$ per cent., $\mathrm{KCl} 0.03$ per cent., $\mathrm{CaCl}_{2} 0.02$ per cent., and $\mathrm{NaHCO}_{3}$ 0.02 per cent. Ins

Distilled water dissolved 1 part neutral hydrochloride in 35 patto Saline solution Ringer's solution

The lessened solubility in the presence of $\mathrm{NaCl}$ is, of course, only an example of the law, well known in physical 
chemistry, that two salts with a common ion lessen each other's solubility, but I had not appreciated that this would liold for the low concentration of $\mathrm{NaCl}$ in these solutions. 'The still lower solubility in Ringer's solution is due to its slight alkalinity, which may lead to the precipitation of the bas:-and also to the fact that it contains a slightly greater number of chloride ions.

It was found that on making up the solution with saline which had been kept for a month the solubility was the same as with fresh saline, but that with Ringer's solution the solubility became les: in proportion to the age of the Ringer's solution-that is, with Ringer's solution which had been standing for a month and a half, the solubility was 1 in 135 . Also if the solution of quinine hydrochloride in Ringer's solution is allowed to stand for one week it is found that quinine is precipitated, only 1 part in 125 remaining dissolved.

These results show that it is advisable to use freshly pre. pared solutions for intravenous injection. By heat quinine hydrochloride can be dissolved in saline or Ringer's solution to the same extent as in distilled water, but there is a tendency for adeposit of crystals to take place in the needle as the solution becomes cooled during injection.

\section{Relative Acidity of Acid Quinine Hydrochloride and} Quinine and Urea Hydrochloride.

The hydrochloride of quinine and urea has been introduced of late years and may be regarded as a substitute for the acid hydrochloride. As regards solubility, each is soluble in less than its own weight of water. It is of importance to find whether quinine and urea hydrochloride differs from the acid hydrochloride in acidity. I have made up solutions containing the same amount of quinine per cent. ; 1.33 per cent. solution of quinine and urea liydrochloride contains the same amount of quinine as a 1 per cent. solution of acid hydrochloride. On titrating these solutions with $\mathrm{N} / 10 \mathrm{NaOH}$, using phenol red as indicator, I found that

$5 \mathrm{c.cm}$. quinine and urea hydrochloride solution $=1.4 \mathrm{c} . \mathrm{cm} . \mathrm{N} / 10 \mathrm{NaOH}$ 5 c.cm. acid quinine hydrochloride solution $=1.3 \mathrm{c.cm} . \mathrm{N} / 10 \mathrm{NaOH}$.

The $\mathbf{P}_{\mathbf{H}}$ of these solutions was then tested, using standard $\mathrm{P}_{\mathrm{H}}$ solutions with methyl orange as indicator. It was found that $\mathrm{P}_{\mathrm{H}}$ of quinine and urea hydrochloride was 3.5 and the $P_{H}$ of acid quinine hydrochloride was 3.7.

It is seen that the acidity of these two drugs, both as shown by the hydrogen ion concentration and the titrable acidity, is practically the same. Thus quinine and urea hydrochloride appears to possess no advantage over acid quinine hydrochloride.

\section{fttemaranda:}

\section{MEDICAL, SURGICAL, OBSTETRICAL.}

\section{FUNCTIONAL AMBLYOPIA.}

During the last two years I have had under my observation ten scholars witl defective vision in whom there was no error of refraction and no discoverable disease to account for the bad rision. The children, when in school, were found to have defective vision and in consequence were sent for treatment.

The sexes were equally divided. Their ages ranged from 9 to 13 years, and their visual acuity, as tested with Snellen's distant types, from 6/18 to $3 / 60$. Both eyes were alike, or nearly so. The refractive conditions, estimated under atropine, showed practically no error, or only slight degrees of hypermetropia or astigmatism. The media and fundi were normal. On placing a $-2 \mathrm{D}$. sph. over an eye the vision was usually made worse, but on adding to this $a+2 D$. sph., the one lens neutralizing the other, the child immediately read right down to $6 / 9$ or $6 / 6$. This manœurre was equally successful in all the cases.

These striking results were due to suggestion, or to withdrawal of psychic inhibition. In one case the fields of vision were tested with a small white object and were found to be contracted down to about 20 degrees. Some could read the test types for near vision, at least for a short time, while their distant vision was very imperfect. All were encouraged to believe that they could read the distant types, and most of them did so ultimately, in a slow, hesitating manner. Swanzy wrote of the "fluctuating vision" in these cases, a condition that we often observe.

All these children were dull and listless, some ready to weep, and others decidedly anaemic. Probably these con. ditions of lowered vitality were partly due to the present industrial depression with consequent unemployment and underfeeding.

Some years ago I reported ${ }^{1}$ the case of a girl who recovered her sight after having been for two years in an institution for the blind; her eyes presented no evidence of disease.

Cambuslang, Glasgow. JAMes Alexander Wilson, O.B.E., M.D.

\section{RUPTURE OF VARICOSE VEINS MIMICKING} ACCIDENTAL HAEMORRHAGE.

A PRIMIPARA, hourly expecting her confinement, on getting up into bed bled profusely. A midwifo was summo on getting up sent for me. I found the patient perturbed but otherwise looking well. The bleeding had stopped and her pulse was slow. I was told that there were no pains and no pigns per vaginam of dilatation of the cervix and no boggy feeling through the fornices.

The possibility of accidental haemorrhage was entertained and a sedative was given. Two days later labour came on and the first stage was without any haemorrhagic abnor. mality - thus ruling out placenta praevia. T'he second stage was delayed, so I put on forceps. The case being primiparous I was surprised to find the anterior vaginal wall bulging down in front of the advancing head. I pushed back this protrusion, and as I did so-gently-I felt my finger perforate the tissues, and $I$ wondered why the anterior vaginal wall should be so fragile. When the head was born there was a gush of blood from the vagina, so I promptly delivered the shoulders; luckily the child was small. There was no tear of the perineum. The blood now poured from the vagina, so I pressed the soft tissues against the symphysis, with happy results, for there was no more bleeding.

Inquiry next day elicited the history of the patient, during her pregnancy, having been examined by a doctor, who told her she had varicose veins on the front wall of her front passage, and that trouble during her confinement might result. She moved out of this doctor's area and forgot to mention to me what she had been told. This varicosity had not been seen by myself or the midwife, as we had only inspected the parts when the patient was recumbent, and she had not thought it worth while to mention this varicosity.

Had the patient presented the signs and symptoms of severe loss of blood when I saw her first I might have packed her vagina as recommended for accidental haemorrhage by the late Dr. Berry Hart in his book, Guide to Midwifery, 1912: "This treatment applies to cases where the cervix is undilated and the uterus not acting" (p. 514)

The above case is a good example of the disadvantage to doctor and to patient of the usual plan of the doctor being booked and then not seeing his patient till the ohild is born or some complication arises.

Dr. Berry Hart in his book says: "Of course the medical attendant should have seen his patient on several occasions before" being called to her in labour; but how many prospective fathers are prepared to meet this expense?

Kilnhurst, nr. Rotherham. Charles J. Hill Aitken, M.D.

\section{KNOT IN UMBILICAL CORD AS A CAUSE OF ACCIDENTAL HAEMORRHAGE.}

The following case may be rare enough to warrant pablication:

Mrs. S., aged 24, second pregnancy, noticed haemorrhage at 6.30 a.m. on May 7 th. She did not expect her confinement for another two weeks. When I saw her at 10.30 a.m. she was considerably collapsed, and still having continuous, though not severe haemorrbage. The uterus was not unduly large and the os admitted two fingers, and was patulous. It was a vertex presentation, and two fingers, and was patulous. It was a vertex presentation, and
there was no sign of placents praevia. There were no "pains,"
and no foetal heart sounds were audible.

An enema, followed by rectal saline, decreased the haemorrhage but failed to produce uterine contractions, as also did 1/2 c.cm. of pituitrin. As at 2.30 p.m. there were still no contractions, I packed the vagina tightly, and this produced the desired effect, os the child was born (dead) at 5.30 p.m. A large clot of blood followed, and immediately afterwards the placenta. The cord, which was longer than average, had a single complete knot in it, and the fotal circulon and separation of the placenta and haemorrhage before labour set in.

The patient had complained of great foetal activity for some days previously.

Madeley, Shropshire.

\section{A. F. Grattan Guinness, M.R.C.S.}

